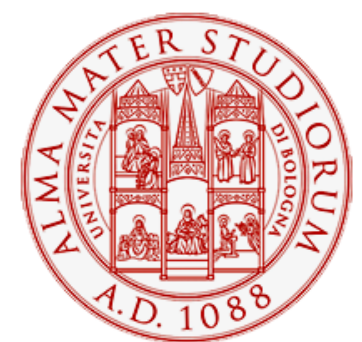

Alma Mater Studiorum - Università di Bologna DEPARTMENT OF ECONOMICS

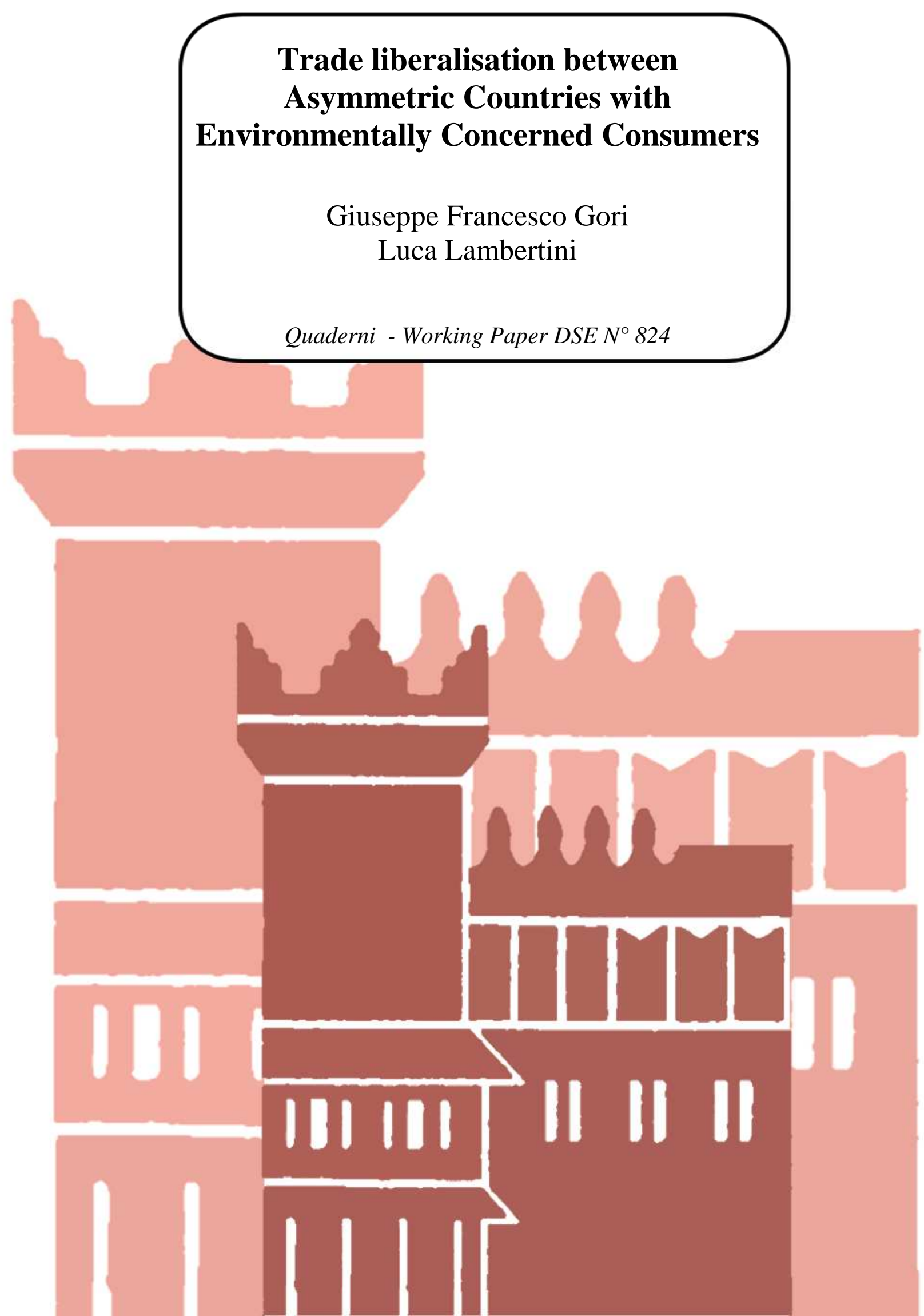




\title{
Trade liberalisation between Asymmetric Countries with Environmentally Concerned Consumers
}

\author{
Giuseppe Francesco Gori* $\quad$ Luca Lambertini ${ }^{\dagger}$
}

April 20, 2012

\begin{abstract}
This paper investigates the impact of free trade on welfare in a two-country world modelled as an international Hotelling duopoly with quadratic transport costs and asymmetric countries, where a negative environmental externality is associated with the consumption of the good produced in the smaller country. Countries' relative sizes as well as the intensity of negative environmental externality affect potential welfare gains of trade liberalisation. In line with Lambertini (1997a) we show that, as long as no trade policy is undertaken by the government of the larger country, trade liberalisation is not feasible since the latter always loses from opening to trade. A subsidy policy in favour of the firm producing the clean good is, on the contrary, shown to give both countries the right incentives to liberalize trade. Allowing for redistributive transfers between countries further extends the parametric range for which trade liberalisation is feasible under the subsidy scheme. The alternative situation, in which the green firm is based in the larger country, is also briefly sketched to find that free trade does give rise to a global welfare increment with no need of accompanying trade policies.
\end{abstract}

JEL Numbers: F12, L13, H23

Keywords: International trade, geographical nation size, spatial competition, environmental externality

\section{Introduction}

In the last two decades, economists have massively contributed to the discussion on the environmental effects of trade liberalisation and the effects of countries' environmental conditions on their competitivity. This task has been carried out taking into consideration different industrial configurations, either Bertrand or Cournot competition as well as different definitions of the environmental damage.

What we propose here is an additional contribution that formally tackles the problem relying on a spatial framework à la Hotelling, were two firms produce an horizontally differentiated good. The comparatively small theoretical literature existing in this area (see Lambertini (1997a); and Tharakan and Thisse (2002)) has indeed pointed out the presence of interesting asymmetric effects on welfare, arising in that specific, partial equilibrium framework. In the spatial framework, in fact - if transport

\footnotetext{
*Department of Economics, University of Bologna. Strada Maggiore 45, 40125 Bologna, Italy. Email: giuseppe.gori@unibo.it.

${ }^{\dagger}$ Department of Economics, University of Bologna. Strada Maggiore 45, 40125 Bologna, Italy. Email: luca.lambertini@unibo.it.
} 
costs are quadratic in distance - the smaller country has been shown to undoubtedly benefit from free trade by increasing its own firm's sales: its firm's profits increase at the expenses of the consumer surplus of the larger country. This also implies that trade liberalisation, although improving welfare at the world level, necessarily has a negative impact on the welfare of the larger among the two countries: if firms can preserve market power via endogenous differentiation, the geographical size matters and trade liberalisation asymmetric effects on welfare are mainly driven by profits dynamics. Our intention is to verify whether taking environmental issues into account may modify this conclusion in favour of a positive symmetric effect of trade liberalisation which, obviously, is a necessary condition for free trade to emerge spontaneously at equilibrium. In our model, asymmetry in size and horizontal product differentiation combine with a few additional features: (i) consumers in larger of the two countries are environmentally concerned, while their fellow consumers abroad are not; as a result, (ii) the firm based in the environmentally aware market is green from the outset, while her equivalent based abroad is brown; and (iii) pollution is taken to be a consequence of consumption, so that it is not transboundary under autarky, while any penetration of the environmentally aware country on the part of the brown firm causes environmentally concerned consumers to experience some degree of environmental externality, increasing in the volume of imports. To this regard, a few aspects require some clarification. First, since in the real world larger countries are generally net exporters of polluting products, in our model, country size is to be intended as the number of consumers with a sufficiently high disposable income which are then supposed to share a similar consumption pattern with analogous consumers worldwide. This allows us to say that large emerging countries (China, India and Brazil) are, de facto, small relative to developed countries such that those of Western Europe. Second, the fact that in our model the smaller (poorer) country's firm is the one producing a brown good may be justified by resorting to the so-called pollution haven hypothesis: poorer countries have a comparative advantage in the production of brown goods, given their laxer pollution policies. ${ }^{1}$

Finally, even if the model encompasses exclusively the special case of contiguous countries, it is perfectly able to account for trade liberalisation effects in the case of geographically distant countries, provided that the negative externality is generated by consumption rather than by production. Our model is therefore suitable for approaching some policy issues: may consumers' environmental awareness, per se, change the distribution of gain and losses stemming from trade liberalisation by limiting the demand of the brown good? Must a tariff/subsidy policy intervene to correct or eliminate altogether this externality? We find that the large country can gain from trade liberalisation only if a reversal of the pattern of trade is feasible, that is, if the smaller country is not so small. In that case, in fact, the former can always adopt a subsidy policy to induce the trade reversal and this, in addition to setting the home emission level to zero, reduces its level abroad.

Our work draws on three strands of the theoretical literature: the first on spatial competition à la Hotelling, the second on the environmental effects of international trade (in the presence of a trade policy) and the third on the environmental effects of consumers' environmental awareness. Suitable background for the first one is available in standard references such as D'Aspremont, Gabszewicz, and Thisse (1979), Lambertini (1997b) and Tabuchi and Thisse (1995) as well as in Lambertini (1997a) and Tharakan and Thisse (2002). The latter two works specifically focus on the effects of international trade in a Hotelling international duopoly and, since they both encompass asymmetry in the size of countries, also represent

\footnotetext{
${ }^{1}$ To this regard, see Copeland and Taylor (2004) for a review.
} 
the most appropriate comparative background for our model. ${ }^{2}$

The second strand of literature is particularly rich and contributions have proceeded in several directions. We may refer the reader to works which merely or primarily attempt to assess the links between trading regimes and environmental outcomes, these being defined in terms of level/incidence of pollution ${ }^{3}$ or in terms of natural resources/environmental capital depletion. ${ }^{4}$ Secondly, a larger part of this literature has essentially faced policy issues, both in terms of environmental policies (price controls, emission tradable permits and pollution quotas) and trade policies. To this regard, comprehensive assessments are provided by Copeland and Taylor (2004) and Copeland (2011) referring both to what concerns the effects of trade liberalisation on environmental policy and the effects of environmental problems on trade policy. ${ }^{5}$ To this regard, issues of particular interest are the use of trade policies to achieve environmental objectives and vice-versa, the adoption of environmental policy in order to distort trade flows. Moreover, a few contributions has focused on the relation between trade, transboundary pollution and climate change. ${ }^{6}$

Concerning the third strand of literature, despite the fact that our model includes a very simple modelisation of environmental awareness, it is reminiscent of previous important contributions such as Conrad (2005), tackling the problem of the effect of environmental awareness on equilibrium prices, product characteristics and market shares of two Hotelling-style firms. Again in a spatial framework, remarkable works are those of Rodríguez-Ibeas (2007) and Clemenz (2010), while Yakita and Yamauchi (2011) adopt a Cournot oligopoly framework with horizontal product differentiation. Papers by Eriksson (2004), Moraga-González and Padrón-Fumero (2002) and Bansal and Gangopadhyay (2003) are largely focus on the relation between the presence of environmentally concerned consumers and the efficacy of

\footnotetext{
${ }^{2}$ The same question is posed in a similar framework by Shachmurove and Spiegel (1995), while Egger and Egger (2007, 2010) analyze the consequences of free trade in a spatial model allowing for a change in the industrial structure and in firms' organization.

${ }^{3}$ See Copeland and Taylor $(2003,2004)$ for an exhaustive review of the literature. As an example, the framework proposed by Copeland and Taylor (1994), is that of a static two-country model where each country produces a continuum of goods differentiated by the degree of greenness (here authors allow the government to set pollution taxes); they find that income is positively correlated with the degree of environmental protection, while, in the presence of a sufficiently unequal distribution of income at the world level, free trade raises pollution. In a similar manner Antweiler, Copeland, and Taylor (2001) introduce a pollution tax which is shown to influence the pattern of trade, coherently with the pollution haven hypothesis: the higher the country's income, the stricter the pollution policy, the higher the comparative advantage in clean good. Finally, Fujiwara (2009) investigates the effects of free trade on global stock of pollution using a two-country differential game model. Additional contributions are the works from Zeng and Zhao (2009), Ederington, Levinson, and Minier (2004) and, in a purely empirical context, Frankel and Rose (2005).

${ }^{4}$ Here, primary references are the papers from Brander and Taylor (1997) and Copeland and Taylor (1999); the former concludes that trade may be welfare reducing for a small country net exporter of diversified resources since it enhances natural resources depletion, while the latter provides an explanation for trade based on spatial separation of incompatible industries due to production-production negative externalities in terms of reduction of environmental capital. Chichilnisky (1994) proposes an explanation of international (North-South) trade based on the difference in the definition of property rights on environmental resources, in her framework, taxing the use of resources in the South leads to increasing extraction. More Recent works are those of Taylor (2011) and Copeland and Taylor (2009). The former develops a model in which open access together with natural resource's fixed price and innovation can explain how international trade can bring about a rapid decline in the environmental capital of a country while the latter link the country's choice of the resource exploitation regime to the dynamics of world prices.

${ }^{5} \mathrm{With}$ respect to the this issue other remarkable references are the works by Neary (2006), Haupt (2006), McAusland (2008) and Bagwell and Staiger (2001).

${ }^{6}$ To this regard see Copeland and Taylor (2005), Fischer and Fox (2009), Gros (2009), Keen and Kotsogiannis (2011) and Holland (2009).
} 
environmental policies, while Espinola-Arredondo and Zhao (2011) try to assess the welfare implications of subsidisation/taxation policies in a linear city model very similar to ours, even if abstracting from the effects of trade.

The remainder of the paper is organized as follows. Section 2 presents the model, the autarkic equilibrium and the the effects of trade liberalisation. Section 3 shows how different trade policies can affect long run social welfare of both countries. Section 4 considers the opposite case in which the larger country is the one where the brown good is produced. Section 5 concludes.

\section{The model}

We rely on the general framework of D'Aspremont, Gabszewicz, and Thisse (1979) as modified by Lambertini (1997a) by introducing asymmetry in countries' size. Two firms operate in a linear world of unit length where firm 1 is necessarily located in country 1 and firm 2 in country 2. Consumers are uniformly distributed over $[0,1]$ with density 1 and that a share $\alpha$ of them belongs to country 1 while the complement to 1 belongs to country 2. Since $\alpha$ is to be intended as the border, asymmetry in countries' sizes is assured by limiting it in the interval $(0,1 / 2)$ so as country 1 is smaller than country 2 . A constant marginal cost of production is common to both firms ${ }^{7}$ and no relocation costs are modeled. We extend the model by supposing existence of an additional asymmetry w.r.t. the environmental impact of consumption, in such a way that consuming the product supplied by firm 1 entails a negative externality, while the good supplied by firm 2 is green. We may justify this assumption by supposing that consumers in country 2 have developed an environmental awareness at some point in the past, while this does not apply to consumers living in country 1 . This has two consequences. The first is the presence of a linear damage function such that country $i$ 's social welfare is reduced by an amount $D_{i}$ which is equal to:

$$
D_{i}=\beta y_{1 i} \quad \text { with } \quad i=1,2,
$$

where $y_{1 i}$ is country $i$ 's total consumption of the brown good produced by firm 1 while $\beta$ represents the emission intensity. The second consequence is the representation of consumer preferences in the two countries. In both, each consumer has a unit demand and consumption yields a constant positive surplus $s$; net utility, however, will or will not account for pollution, depending on the location of a specific consumer. Consider first an individual based in country 1. For him/her, net utility is defined as:

$$
U_{1}=s-t d_{i}^{2}-p_{i}, \quad i=1,2,
$$

where $p_{i}$ is the price of variety $i$ and $t d_{i}^{2}$ is the transportation cost, quadratic in distance $d_{i}$ from firm $i$; the latter is defined as:

$$
d_{i}=m-x_{i},
$$

where $m$ and $x_{i}$ are, respectively, the generic consumer's and firm's $i$ locations.

Looking instead at a consumer based in country 2, the corresponding net surplus is defined as:

$$
U_{2}=s-t d_{i}^{2}-p_{i}-D_{2}, \quad i=1,2,
$$

where $D_{2}=0$ in autarky. For the sake of simplicity, and without further loss of generality, we also normalize the transportation cost rate $t$ to one.

\footnotetext{
${ }^{7}$ Here assumed to be nil without loss of generality.
} 


\subsection{Autarkic equilibrium}

In autarky, the monopoly price set by each firm nullifies the net surplus $U_{i}$ of the marginal consumers, i.e., those living at country borders $0, \alpha$ or 1 :

$$
p_{1}^{A}=s-\left(\alpha-x_{1}^{A}\right)^{2} ; \quad p_{2}^{A}=s-\left(1-x_{2}^{A}\right)^{2},
$$

where $x_{1}^{A}=\alpha / 2$ and $x_{2}^{A}=(\alpha+1) / 2$ are the socially optimal locations in autarky (denoted by superscript $A)$, minimizing total transportation costs in each country:

$$
T C_{1}^{A}=\int_{0}^{\alpha}\left(d_{1}\right)^{2} d m ; \quad T C_{2}^{A}=\int_{\alpha}^{1}\left(d_{2}\right)^{2} d m
$$

These of course also appears in the definition of consumer surpluses:

$$
C S_{1}^{A}=\int_{0}^{\alpha}\left[s-p_{1}-\left(d_{1}\right)^{2}\right] d m ; \quad C S_{2}^{A}=\int_{\alpha}^{1}\left[s-p_{2}-\left(d_{2}\right)^{2}\right] d m .
$$

As for social welfare in country 1 and 2 , respectively defined as:

$$
S W_{1}^{A}=\pi_{1}^{A}+C S_{1}^{A}-\beta \alpha ; \quad S W_{2}^{A}=\pi_{2}^{A}+C S_{2}^{A}
$$

the autarky equilibrium yields:

$$
S W_{1}^{A}=\alpha\left(s-\frac{1}{12} \alpha^{2}-\beta\right) ; \quad S W_{2}^{A}=(1-\alpha)\left[s-\frac{1}{12}(1-\alpha)^{2}\right] .
$$

Note that while social welfare of country 1 is negatively affected by consumption of the brown good $\left(y_{11}^{A}=\right.$ $\alpha$ ), this does not affect social welfare of country 2 (since the externality is generated by consumption, no transboundary pollution is supposed to exist). Moreover, non negativity of both prices requires imposing a condition on the level of gross consumer surplus common to all consumers, which is (see Appendix A.1):

$$
s \geq s_{p}^{A}=\frac{1}{4}\left(1-2 \alpha+\alpha^{2}\right) .
$$

The autarkic equilibrium definitions of other relevant magnitudes are reported in Appendix A.

\subsection{The free trade equilibrium}

In this section we evaluate the consequences of trade liberalisation by allowing firms to relocate and adjust prices in order to maximize profits. The only restriction we pose is that firms cannot relocate outside the unit segment measuring the size of this two-country economy. ${ }^{8}$ The first step consists in understanding whether the environmental externality can affect the equilibrium partition of demand under free trade, or not.

Lemma 1 [Demand partition and environmental awareness] The position of the indifferent consumer is independent of emission intensity (or environmental awareness).

\footnotetext{
${ }^{8}$ In this respect, the present approach differs from what is typically accepted in other papers using the same model (Tabuchi and Thisse (1995); Lambertini (1997b)). The reason is that here the single spatial dimension necessarily accounts for both possible interpretations, as a geographical space and as the preference space.
} 
Proof. The indifferent consumer's location $\hat{m}$ (i.e., the identity of the consumer which determining market shares) is identified by the following condition:

$$
p_{1}^{T}+\left(\hat{m}-x_{1}^{T}\right)^{2}+\beta(\hat{m}-\alpha)=p_{2}^{T}+\left(\hat{m}-x_{2}^{T}\right)^{2}+\beta(\hat{m}-\alpha),
$$

where superscript $T$ stands for free trade and the term $\beta(\hat{m}-\alpha)$ represents the value of the damage function $D_{2}$ when $\hat{m}-\alpha$ consumers of country 2 buy from firm 1 . This condition is then defined only for $\hat{m}>\alpha$ which implies the marginal consumer has to be located in country 2 .

Solving (2.9) for $\hat{m}$ then yields:

$$
\hat{m}=\frac{p_{1}^{T}-p_{2}^{T}+\left(x_{1}^{T}\right)^{2}-\left(x_{2}^{T}\right)^{2}}{2\left(x_{1}^{T}-x_{2}^{T}\right)} .
$$

Market demands are therefore defined as:

$$
y_{1}^{T}=\hat{m}=\left\{\begin{array}{lll}
\hat{m} \quad \text { iff } & \hat{m} \in(0,1) ; \\
1 & \text { iff } \quad \hat{m} \geq 1 ; \\
0 & \text { iff } \quad \hat{m} \leq 0 .
\end{array} \quad ; \quad y_{2}^{T}=1-\hat{m}=\left\{\begin{array}{l}
1-\hat{m} \quad \text { iff } 1-\hat{m} \in(0,1) ; \\
1 \quad \text { iff } 1-\hat{m} \geq 1 ; \\
0 \quad \text { iff } \quad 1-\hat{m} \leq 0 .
\end{array} .\right.\right.
$$

That is, since consumers in country 2 incorporate the environmental externality irrespectively of their consumption choice (whether green or brown), the volume of firm 1's exports to country 2 is altogether unaffected by the environmental awareness of the recipients. As a consequence, the two-stage subgame perfect equilibrium in pure strategies arising under free trade coincides with Lambertini (1997a), with maximum differentiation at $x_{1}^{T}=0, x_{2}^{T}=1$ and equilibrium prices and profits $p_{1}^{L}=p_{2}^{L}=t=1$; and $\pi_{1}^{L}=\pi_{2}^{L}=\frac{t}{2}=\frac{1}{2}$. And, of course, $\hat{m}=\frac{1}{2}$.

No additional condition on $s, \alpha, \beta$ is thus required to assure the non-negativity of prices and profits while a new condition on gross surplus must hold in order for full market coverage to be sustainable, i.e.,

$$
s \geq s_{M C}^{T}=\frac{1}{4}[5+2 \beta(1-2 \alpha)],
$$

where

$$
\left.s_{M C}^{T}>s_{p}^{A} \quad \forall \alpha \in\right] 0,1 / 2[, \beta \in] 0,1[,
$$

so as condition for market coverage in the long run also assures non-negativity of prices in autarky. Concerning price dynamics in the shift from autarky to free trade, we have that $p_{1}^{L}<p_{1}^{A}$ and $p_{2}^{L}<p_{2}^{A}$ $\forall \alpha \in(0,1 / 2), \beta \in(0,1)$. Remaining magnitudes are reported in Appendix A.

\subsection{Trade liberalisation effects}

The results described in the previous subsections allow us to analyze the effects of trade liberalisation in terms of changes in the relevant magnitudes. These are summarised in the following

Proposition 1 [Welfare] Trade liberalisation causes (i) an increase in the welfare of the smaller country if the latter is sufficiently small; (ii) a decrease in the welfare of the larger country; (iii) a decrease in the welfare at the world level.

Proof. See Appendix A. 
Hence, since free trade is unambiguously detrimental for the larger country (regardless of the degree of asymmetry in size and the emission intensity), trade opening is a strictly dominated strategy for the latter. From this it follows that trade liberalisation is unlikely to occur, which is true even if allowing for side payments, since the gain in social welfare for the smaller country is never high enough to compensate for the loss borne by the larger one.

In order to understand why trade liberalisation has always a negative impact on the larger country's welfare as well as on the smaller country's welfare in most of the cases, we now proceed to decompose the effects on social welfare into two separate elements, namely, the consequences of trade on firms' profits as well as on consumer surpluses. As to the latter magnitude, the following holds:

Proposition 2 [Consumer Surplus] Trade liberalisation, by decreasing both prices, determines an increase in consumer surplus in both countries.

\section{Proof. See Appendix A.}

With free trade, instantaneous firms' relocation in correspondence of the world economy's borders entails an increase in transportation costs for both countries. Thus, the positive effect on worldwide consumer surplus has to be necessarily determined by the decrease in prices, due to the Bertrand competition arising in the international duopoly setting.

We now move to consider how trade liberalisation affects profits in the long run.

Proposition 3 [Profits] Free trade brings about an increase in the profit accruing to the firm based in the smaller country provided that the latter is sufficiently small, while it always hurts the firm based in the larger country.

Proof. As far as firm 2 is concerned, the statement contained in in Proposition 3 is intuitive: since trade liberalisation entails diminishing demand, the negative quantity effect sums up to the negative price effect and profits shrink, regardless of $\alpha$ and $\beta$. As to Firm 1 we have that:

$$
\begin{gathered}
\pi_{1}^{T}-\pi_{1}^{A} \quad=\quad \frac{1}{4}\left[2-\alpha\left(4 s-\alpha^{2}\right)\right]>0, \\
\text { iff } \quad s<s_{1}^{T}=\frac{2+\alpha^{3}}{4 \alpha},
\end{gathered}
$$

where $s_{1}^{T}$ is strictly decreasing in $\alpha$, with $\left.s_{1}^{T} \in\right] \infty, \frac{17}{16}[$ as $\alpha \in] 0, \frac{1}{2}\left[\right.$. Moreover $s<s_{1}^{T}$ is necessary but not sufficient condition for (2.13) to hold in equilibrium since also $s_{1}^{T}>s_{M C}^{T}$, which assures non-negativity of prices and full market coverage, has to be met. The latter is verified for $\alpha \in] 0,-1+\sqrt{2} \simeq 0.414[$ and $\beta \in] 0, \min \left[\frac{2-5 \alpha+\alpha^{3}}{2 \alpha-4 \alpha^{2}}, 1\right]\left[.^{9}\right.$

Thus, as far as firm 1 is concerned, the gain in profits associated to trade liberalisation is decreasing in $\alpha$. An higher $\alpha$, in fact, strengthens price competition and, moreover, reduces the positive quantity effect of trade liberalisation $\left(\frac{1}{2}-\alpha\right)$ : since equilibrium location of the marginal consumer is not affected by the relative size of country 1 , the gain in demand accruing to firm 1 is decreasing in $\alpha$.

Moreover, from (2.13), the gain in profits is decreasing in the individual consumer surplus $s$ too. This is due to the fact that a higher $s$, via an increase in the price of the brown variety, raises profits autarkic equilibrium level, though leaving unaffected the corresponding level in free trade. ${ }^{10}$ This also formally

\footnotetext{
${ }^{9}$ This also implies that $(2.13)$ holds, regardless of the level of $\beta$, for $\left.\alpha \in\right] 0, \frac{1}{2}(\sqrt{33}-5) \simeq 0.372[$.

${ }^{10}$ Since, when duopolistic competition arises, exactly the same effect is shown to be entirely transferred to consumer surpluses (see Appendix (A.1) and (A.2)).
} 
explains the existence of a substitution effect between the asymmetry in size and the individual consumer surplus, that is, why threshold $s_{1}^{T}$ is decreasing in $\alpha$ : when countries are very similar in size, the autarkic profits must be very low to preserve the existence of a gain associated to trade liberalisation, since the latter entails a lower quantity effect .

Lastly, if country 1 is sufficiently large $(\alpha>0.372)$, we have identified an upper threshold for the emission intensity $\left(\beta=\frac{2-5 \alpha+\alpha^{3}}{2 \alpha-4 \alpha^{2}}\right)$. If $\beta>\frac{2-5 \alpha+\alpha^{3}}{2 \alpha-4 \alpha^{2}}$, it follows that $s_{1}^{T}<s_{M C}^{T}$ that is for all levels of $s$ which assure non-negativity of prices and full market coverage firm 1 cannot gain from free trade.

Hence, trade liberalisation has asymmetric effects on firms' profits: while it unambiguously implies a loss for firm 2 it may favour firm 1 . Since free trade brings about a decrease in both equilibrium prices, this is necessarily due to the difference in the sign of the quantity effect which is clearly negative for the larger country and positive for the smaller. Propositions 1-3 have been summarised in Table 1.

\begin{tabular}{ccr} 
& \multicolumn{2}{c}{ Country } \\
\cline { 2 - 3 } & 1 & 2 \\
\hline $\mathrm{TC}$ & $\uparrow$ & $\uparrow$ \\
$\mathrm{CS}$ & $\uparrow$ & $\uparrow$ \\
$\mathrm{p}$ & $\downarrow$ & $\downarrow$ \\
$\mathrm{y}$ & $\uparrow$ & $\downarrow$ \\
$\pi$ & $\uparrow$ & $\downarrow$ \\
\hline $\mathrm{SW}$ & $\uparrow$ & $\downarrow$ \\
\hline
\end{tabular}

Table 1: Trade liberalisation, signs of magnitudes' variations.

To conclude, the shift from autarkic to free trade equilibrium has not univocal implications from the point of view of social welfare of country 1: until country 1 is small enough $(\alpha<0.4735)$, in fact, the gain in consumer surplus for its inhabitants outweighs any loss in firm's profits, regardless of the level of $\beta$ and $s$; for higher $\alpha$ the opposite is true: the dynamic of profits is unambiguously negative and the gain in consumer surplus is reduced. The intuition behind the latter effect is straightforward: the price that firm 1 can sustain in autarky is decreasing in $\alpha$ due to the fact that she must compensate for higher transportation costs borne by consumers, while is constant in free trade; this sums up with the fact that $\alpha$ has a stronger positive effect on the free trade equilibrium level of transportation costs as compared to those of autarky.

For what concerns country 2, we conclude that, though welfare reducing, trade liberalisation acts in favour of a redistribution of welfare from the firm to the consumers: the price effect stemming from duopolisitic competition raises the consumer surplus, and, together with an output reduction, implies a decrease in the profits accruing to the domestic firm.

\section{Trade policy}

We now proceed to analyze the long-run consequences of trade liberalisation when the government of country 2, which is otherwise unambiguously suffering from the opening of trade, implements a trade policy. To this end we define two policies: a linear tariff weighted by the emission intensity - which is indeed formally equivalent to a Pigouvian tax on imports - and a subsidy for firm 2, where the latter is 
supposed to be financed by an equivalent decrease in country 2's social welfare.

\subsection{Import Tariff}

We first suppose that country 2's government levies a tariff $\tau>0$ on the negative externality generated by the volume of the imported brown variety, so that the profits of firm 1 are lowered by an amount equal to: ${ }^{11}$

$$
\tau \beta\left(\hat{m}_{T \tau}-\alpha\right)
$$

We can then write:

$$
\pi_{1}^{T \tau}=p_{1}^{T \tau} \hat{m}_{T \tau}-\tau \beta\left(\hat{m}_{T \tau}-\alpha\right)
$$

and

$$
S W_{2}^{T \tau}=\pi_{2}^{T \tau}+C S_{2}^{T \tau}-\beta\left(\hat{m}_{T \tau}-\alpha\right)+\tau \beta\left(\hat{m}_{T \tau}-\alpha\right),
$$

where $T \tau$ stands for trade with tariff. In equilibrium, social welfare of country 2 is thus supposed to be augmented by an amount equal to the gross tariff income; the definition of all other magnitudes is unchanged w.r.t. the case described in section 3. Again, the equilibrium arising is such that $x_{1}^{T \tau}=0$ and $x_{2}^{T \tau}=1$, implying the following marginal consumer's equilibrium location:

$$
\hat{m}_{T \tau}=\frac{1}{6}(3-\beta \tau) ;
$$

while equilibrium prices are $p_{1}^{T \tau}=1+\frac{2 \beta \tau}{3} ; p_{2}^{T \tau}=1+\frac{\beta \tau}{3}$. From the condition of non negativity of country 2's imports $\left(\hat{m}_{T \tau}-\alpha>0\right)$ we can derive the maximum admissible level of the tariff $\tau$ :

$$
\bar{\tau}=\frac{3-6 \alpha}{\beta} .
$$

For each $\tau>\bar{\tau}$, the model thus predicts a reversal of trade flows with $\hat{m}_{T \tau}<\alpha$; this would formally translate the tariff into a subsidy for firm 1, which, clearly, is not among the feasible policies available to country 2's government, and would invalidate the definition of the demand system. Full market coverage is now assured if consumers' gross surplus is greater than:

$$
s_{M C}^{T \tau}=\frac{1}{36}\left(45+18 \beta-36 \alpha \beta+18 \beta \tau-6 \beta^{2} \tau+\beta^{2} \tau^{2}\right),
$$

where, again, $\left.s_{M C}^{T \tau}>s_{p}^{A} \forall \alpha \in\right] 0,1 / 2[, \quad \beta \in] 0,1[, \quad \tau>0$; while the non negativity of both prices is always verified.

The objective function of the government of country 2 is then:

$$
\max _{\tau} S W_{2}^{T \tau} \quad \text { s.t. } \quad \tau<\bar{\tau},
$$

which yields:

$$
\left.\tau^{*}=\frac{2-2 \alpha+\beta}{\beta} \quad \forall \alpha \in\right] 0, \frac{1}{4}[, \quad \beta \in] 0,1-4 \alpha[.
$$

Note that optimal tariff $\tau^{*}$ is decreasing in both $\beta$ and $\alpha$. For $\tau=\tau^{*}$ the marginal consumer locates at:

$$
\hat{m}_{T \tau}^{*}=\frac{1+2 \alpha-\beta}{6} .
$$

\footnotetext{
${ }^{11}$ Note that this formulation implies that the optimal tariff may effectively result in a trade policy instrument and not only in an environmental policy one since, in principle, its level may be either more or less than compensate the value of the damage function $D_{2}$.
} 
Thus, for $\beta \in] 1-4 \alpha, 1\left[\right.$, country 2's government cannot implement $\tau^{*}$ since $\tau^{*}>\bar{\tau}$, it will then necessarily choose a sub-optimal tariff $\tau=\bar{\tau}$ in order to maximize social welfare. ${ }^{12}$ Indeed, for all $0<\tau<\tau^{*}$ :

$$
\left.\frac{\partial S W_{2}^{T \tau}}{\partial \tau}=\frac{1}{12}\left[2 \beta(2-2 \alpha+\beta)-2 \beta^{2} \tau\right]>0 \quad \forall \alpha \in\right] 0, \frac{1}{4}[, \beta \in] 1-4 \alpha, 1[.
$$

The reason for optimal tariff never restoring autarky for $\beta<1-4 \alpha$, is that, in correspondence of $\tau=\tau^{*}<\bar{\tau}$, a higher tariff would imply, via higher prices, a reduction in consumers' surplus of country 2 strictly greater than the gain in firm 2 profits and in gross tariff revenues. For very low $\alpha$ and $\beta$ a full import substitution obtained through a tariff is thus not feasible, implying a too high cost to be borne by consumers. Equilibrium definitions of magnitudes relatives to both $\tau=\tau^{*}$ and $\tau=\bar{\tau}$ cases are reported in Appendix B.

If the government of country 2 levies the optimal tariff $\tau=\tau^{*}$, we can state what follows:

Proposition 4 [Tariff] There exists no import tariff whereby the larger country's welfare exceeds its autarkic level.

Proof. In order to prove the proposition it is sufficient to observe that:

$$
S W_{2}^{T \tau}-S W_{2}^{A}=\frac{1}{12}\left[\alpha+7 \alpha^{2}+3 \alpha^{3}+8 \alpha \beta+(\beta-2) \beta-2\right] ;
$$

is strictly negative over the admissible range of parameters $\alpha$ and $\beta$.

Hence, for what concerns country 2, an optimal tariff is never effective in determining an increase in social welfare of the same country as compared to the autarkic equilibrium. The reason basically lies in the fact that the tariff itself does not suffice to raise free trade profits over the autarkic equilibrium level. An optimal tariff, in fact, never restores autarky, and then, always implies a negative quantity effect for firm 2 sales, associated with trade liberalisation. ${ }^{13}$

What stated so far, obviously holds even in the case a suboptimal tariff $\tau=\bar{\tau}$ is levied, for $\alpha \in] 0, \frac{1}{2}[$ and $\beta \in] \max [1-4 \alpha, 0], 1[$. As for country 1 , see Appendix B for a detailed assessment of the effects of trade liberalisation in the presence of an optimal tariff $\tau^{*}$.

\subsection{Subsidisation and trade reversal}

In the last subsection we have identified the parametric range in which an optimal tariff can be levied by the government of country 2. We have also stated that, outside this range, if the government wants to impose an import tariff, it must choose a sub-optimal level of the latter, that is the one restoring autarky, $\tau=\bar{\tau}$. As an alternative to this, the government may undertake an export subsidy policy. The latter is obviously defined only for $\hat{m}-\alpha<0$, that is, the marginal consumer has to be located in country 1 . This also implies that the demand system has to be newly defined, in order to account for the trade flow reversal. Marginal consumer is thus now identified by solving the following condition:

$$
p_{1}^{T \theta}+\left(\hat{m}_{T \theta}-x_{1}^{T \theta}\right)^{2}+\beta \hat{m}_{T \theta}=p_{2}^{T \theta}+\left(\hat{m}_{T \theta}-x_{2}^{T \theta}\right)^{2}+\beta \hat{m}_{T \theta},
$$

\footnotetext{
${ }^{12}$ Note that, $\left.\alpha \in\right] \frac{1}{4}, \frac{1}{2}$ [ is sufficient but not necessary condition for $\tau^{*}>\bar{\tau}$.

${ }^{13}$ Notwithstanding this, with a tariff, a smaller part of consumers living in country 2 switches to firm 1, and price competition is undoubtedly relaxed. This implies that trade liberalisation necessarily reduces profits of firm 2 by a lesser amount as compared to the case in which no tariff is levied. On the consumers' side, the decrease in surplus due to higher prices is partially compensated by the gross tariff revenues. Since the positive effect exerted by the tariff on profits is not fully compensated by the corresponding negative effect on consumer surplus, we can state that, with regards to the larger country, the tariff acts in limiting the negative effect of trade liberalisation on the social welfare.
} 
where apex $T \theta$ stands for trade with subsidy. The latter condition, by Lemma 1, yields the same results as in (2.10-2.11).

If we now suppose that country 2's government provides to firm 2 a subsidy $\theta>0$ for each of the $\alpha-\hat{m}_{T \theta}$ units of green good export to country 1, profits of firm 2 become:

$$
\pi_{2}^{T \theta}=p_{2}^{T \theta} \hat{m}_{T \theta}+\theta\left(\alpha-\hat{m}_{T \theta}\right)
$$

while countries' social welfares:

$$
S W_{1}^{T \theta}=\pi_{1}^{T \theta}+C S_{1}^{T \theta}-\beta \hat{m}_{T \theta} ; \quad S W_{2}^{T \theta}=\pi_{2}^{T \theta}+C S_{2}^{T \theta}-\theta\left(\alpha-\hat{m}_{T \theta}\right) ;
$$

From (3.11), equilibrium social welfare of country 2 is supposed to be reduced by an amount equal to the subsidy provided to firm 2; this amount can be higher or lower than the negative externality suffered by the community in case of importing the brown good. As for country 1, the externality in consumption hurts social welfare by a lesser amount w.r.t. the framework analyzed in section 2 (see (2.9)), since now a part of consumers switches to the green good produced by firm 2. Again, the equilibrium arising is such that $x_{1}^{T \theta}=0$ and $x_{2}^{T \theta}=1$, implying the following marginal consumer's equilibrium location:

$$
\hat{m}_{T \theta}=\frac{3-\theta}{6} ;
$$

where the latter is obviously decreasing in $\theta$, while equilibrium prices are: $p_{1}^{T \theta}=1-\frac{\theta}{3} ; p_{2}^{T \theta}=1-\frac{2 \theta}{3}$. Note that both prices are decreasing in $\theta$, that is the subsidy strengthens the price competition stemming from trade liberalisation; this obviously happens since subsidised firm 2 can now sustain a lower price. Non negativity of both prices is verified for $\theta \in] 0, \frac{3}{2}[$. From the condition of non-negativity of country 1 's imports $\left(\hat{m}_{T \theta}-\alpha<0\right)$ we can derive minimum level of the subsidy $\theta$ :

$$
\bar{\theta}=3-6 \alpha .
$$

The latter condition is necessary since, similarly to what underlined in the preceding subsection, for each $\theta<\bar{\theta}$ the model would predict a reversal of trade flows with $\hat{m}_{T \theta}>\alpha$; which would, again, invalidate the demand system and translate the subsidy into a tariff for firm 2, proportional to the externality generated by the consumption of firm 1's imported output. Full market coverage is now assured if consumers' surplus is greater than:

$$
s_{M C}^{T \theta}=\frac{1}{36}\left(45-18 \beta+36 \alpha \beta-18 \theta+6 \beta \theta+\theta^{2}\right),
$$

where, again, $\left.s_{M C}^{T \theta}>s_{p}^{A} \forall \alpha \in\right] 0,1 / 2[, \quad \beta \in] 0,1[, \quad \theta \in] 0, \frac{3}{2}[$.

Country 2' governments objective function is then:

$$
\max _{\theta} S W_{2}^{T \theta} \quad \text { s.t. } \quad \theta \geq \bar{\theta},
$$

which yields:

$$
\left.\left.\theta^{*}=\frac{3}{4}(3-4 \alpha) \quad \forall \alpha \in\right] \frac{1}{4}, \frac{1}{2}[, \quad \beta \in] 0,1\right] .
$$

For $\theta=\theta^{*}$ the marginal consumer locates at:

$$
\hat{m}_{T \theta}^{*}=\frac{4(1+\alpha)-3}{8} .
$$

Note that, for higher $\alpha$, the gain in demand for firm $2\left(\alpha-\hat{m}_{T \theta}^{*}\right)$ is necessarily higher; this amounts to saying that $\theta$ can be fixed to a lower level in order to obtain an equivalent rise in profits $\left(\frac{\partial \theta^{*}}{\partial \alpha}<0\right)$. 
For $\theta>\theta^{*}$, in fact, firm 2' s demand would rise, accompanied by an even higher price competition; the consequent increase in consumer surplus of inhabitants of country 2 would then be not high enough to repay the increase in subsidy expenditure plus the decrease in firm 2 profits. The subsidy, though directly accruing to firm 2, is undoubtedly acting in favour of a redistribution from firm 2's profits to consumer surplus.

For $\alpha \in] 0,1 / 4\left[\right.$ country 2 's government cannot implement $\theta^{*}$ since $\theta^{*}<\bar{\theta}$, nor a non-optimal tariff $\theta=\bar{\theta}$, since the latter would imply a negative price for the brown good.

Under the hypothesis that Government of country 2 levies a $\theta^{*}$ tariff, we can thus state what follows:

Proposition 5 [Welfare with Subsidy]The long-run effect of trade liberalisation on social welfare consists in: (i) an increase in the welfare of the smaller country for a sufficiently high emission intensity and a sufficiently small asymmetry in size between the two countries; (ii) an increase in the welfare of the larger country if the asymmetry in size is sufficiently small and (iii) an increase in the welfare at the world level for a wider parameters' range w.r.t. the one assuring that both (i) and (ii) hold.

Proof. In order to prove part (i) of Proposition 1 is sufficient to observe that, for $\left.\theta=\theta^{*}, \alpha \in\right] \frac{1}{4}, \frac{1}{2}[$ and $\beta \in] 0,1[$ :

$$
\begin{gathered}
S W_{1}^{\mathbf{T} \theta}-S W_{1}^{A}=\frac{1}{64}[3-8 \alpha(1+2 \alpha(1+\alpha)-4 \beta)-8 \beta]>0 \\
\quad \text { iff } \quad \beta \in] \frac{3-8 \alpha[1+2 \alpha(1+\alpha)]}{8-32 \alpha}, 1[
\end{gathered}
$$

while, for what concerns part (ii):

$$
\begin{gathered}
S W_{2}^{\mathbf{T} \theta}-S W_{2}^{A}=\frac{1}{12}\left[\alpha+7 \alpha^{2}+3 \alpha^{3}+8 \alpha \beta+(\beta-2) \beta-2\right]>0 \\
\quad \text { iff } \quad \alpha \in] 0.452,0.5[.
\end{gathered}
$$

For what concerns the last claim in the proposition:

$$
\begin{aligned}
& S W^{\mathbf{T} \theta}-S W^{A}= \frac{1}{64}[8 \alpha(1+4 \beta)-9-8 \beta]>0 \\
&\text { iff } \quad \alpha \in] 0.425,0.5[, \quad \beta \in] \frac{8 \alpha-9}{8-32 \alpha}, 1[.
\end{aligned}
$$

The way trade liberalisation affects profits and consumer surpluses is summarised in the following:

Proposition 6 [Profits and Consumer Surpluses with Subsidy] Free trade, through price effect, brings about (i) an increase in consumer surpluses of both countries; (ii) a decrease in profits accruing to both firms.

Proof. See Appendix B.

Hence, differently from the import tariff policy (see Proposition 4), the subsidy policy may entail a rise in the social welfare of country 2 without necessarily hurting country 1; this requires country 1 to be sufficiently large and the emission intensity to be sufficiently high. 
A higher $\alpha$, through a lower equilibrium subsidy $\theta^{*}$ implies a lower transfer from consumers/inhabitants of country 2 to firm 2; moreover, it limits the negative effect on firm 2 profits and the positive effect on consumer surplus associated with any positive subsidy, since price competition is relaxed. The former two effects are shown to be always stronger than the latter ${ }^{14}$ implying that the marginal effect of $\alpha$ on free trade social welfare of country 2 is strictly positive. Moreover, this is shown to be always greater than the marginal effect on the social welfare in autarky, since $\frac{\partial S W_{2}^{A}}{\partial \alpha}<0$; in that case, in fact, a reduction in the asymmetry between countries entails a decrease in the profits and in the consumer surplus of country 2 , where the former effect is driven by the decrease in demand and the latter by the increase in the price of the green good.

For what concerns country 1 , the effect of $\alpha$ is not a priori defined and depends on the level of $\beta{ }^{15}$ Consequently, for a higher $\beta$, we observe an increase in the burden of externality borne by inhabitants of country 1 which is clearly higher in autarky than in free trade. In the latter case, in fact, some of them switch to the clean good. Thus, given

$$
\frac{\partial S W_{1}^{A}}{\partial \beta}<\frac{\partial S W_{1}^{T \theta}}{\partial \beta}<0
$$

a higher emission intensity, though strictly depressing the social welfare, is always associated with an increase in the differential between its post and pre trade liberalisation equilibrium values.

Proven that $\beta$ is high enough to account for this positive effect of trade liberalisation, even $\alpha$ has to be high enough. Size of the smaller country in fact: (i) raises free trade equilibrium profits through an increase in price and demand $\left(\frac{\partial \hat{m}_{T \theta}^{*}}{\partial \alpha}>0\right.$ ), (ii) raises consumer surplus (proven that $s>\frac{1}{8}\left(3+12 \alpha+8 \alpha^{2}\right)$ ) and (iii) it determines an increase in the burden of externality borne by the inhabitants of country 1 .

Consequently, for high $\beta$ and low $\alpha$ the gains from trade liberalisation accruing to country 1 only consist in lower emissions and in a higher consumer surplus, which are not enough to compensate for the loss in profits; for a high $\alpha$ and a low $\beta$ the opposite is true: both the loss in profits and the emissions are strongly reduced by trade liberalisation, but this is accompanied by a higher reduction in consumer surplus. The latter considerations entails claim (i) in Proposition 5.

\subsection{Discussion}

Along this section we have analyzed the effects of trade liberalisation under the hypothesis of country 2 alternatively undertaking two policies in order to contain trade liberalisation's negative effect, the latter being even reinforced by the externality stemming from consumption of the imported brown good (see section 2). We may now take a closer look at the feasibility of trade liberalisation itself, considered as the outcome of a game where both countries' payoffs are represented by social welfare gains w.r.t. the autarkic equilibrium. Figure 1 provides an exhaustive summary of the parameters' ranges characterizing different results in terms of social welfare dynamics from autarky to free trade, for both countries. We may firstly distinguish three ranges, delimiting the feasibility of both policies. According to results so far provided, for $\alpha \in] 0,0.25[$ and $\beta \in] 0,1-4 \alpha$, the feasible policy is an optimal tariff $\tau=\tau^{*}$; for $\left.\alpha \in\right] 0,0.25[$ and $\beta \in] 1-4 \alpha, 1$, only a sub-optimal tariff policy is allowed and, lastly, for $\alpha \in] 0.25,0.5[$, the government may only choose between an optimal subsidy $\theta=\theta^{*}$ or a suboptimal tariff $\tau=\bar{\tau}$. Moreover, in the second 
range, since $\Delta S W_{2}^{A, T \theta}>\Delta S W_{2}^{A, T \bar{\tau}}$, the government will necessarily choose a subsidy policy. ${ }^{16}$

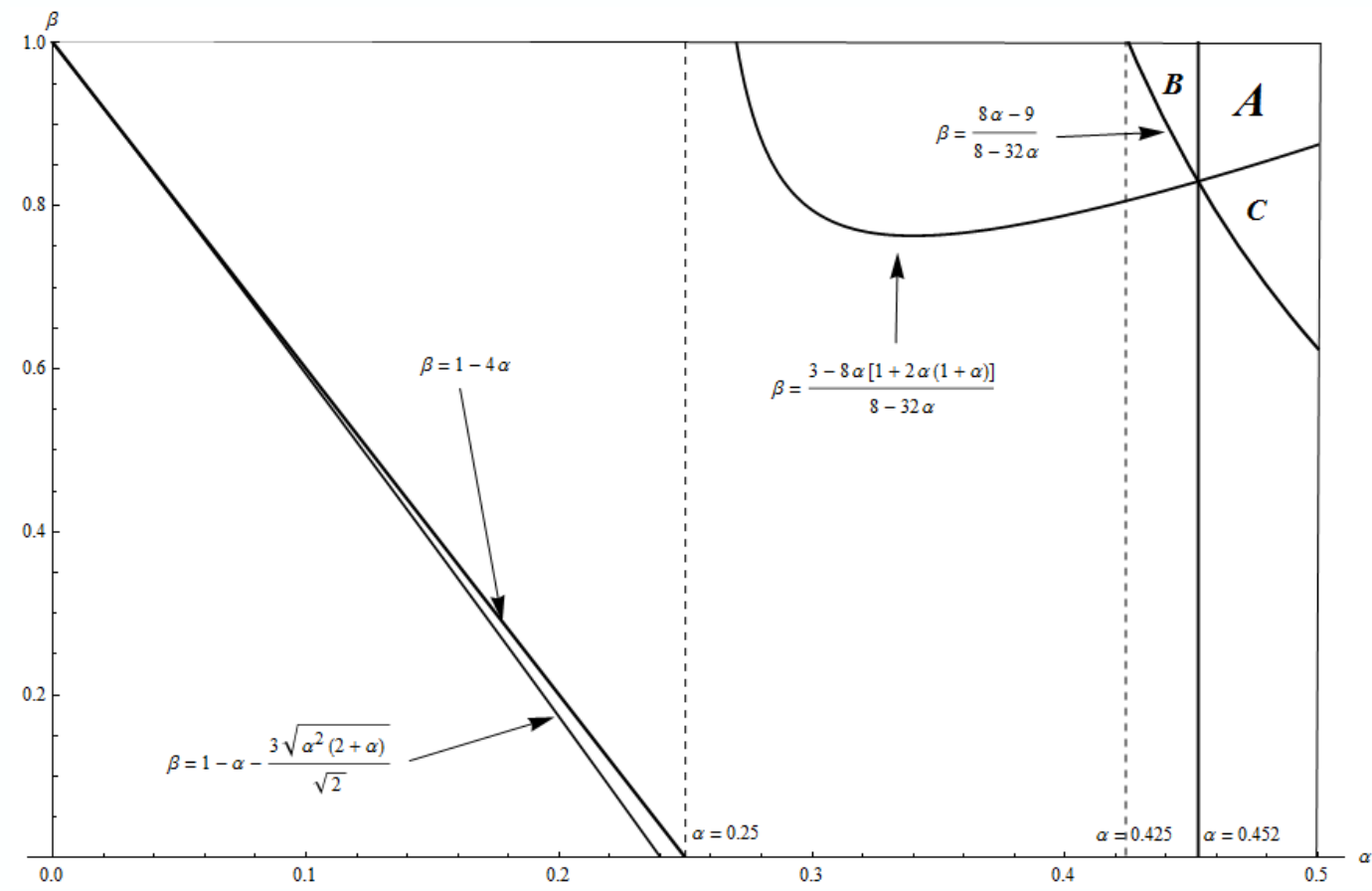

Figure 1: Welfare effects of trade liberalisation with tariff and subsidy, parameters' ranges

In addition to this, from Proposition 4 and 6 , the parameters' range corresponding to area $A$ :

$$
\alpha \in] 0.452,0.5[; \quad \beta \in] \frac{3-8 \alpha[1+2 \alpha(1+\alpha)]}{8-32 \alpha}, 1[
$$

is the only one which is compatible with a Nash bargaining solution, since it is associated with strictly positive $\Delta S W_{1}^{A, T \theta}$ and $\Delta S W_{2}^{A, T \theta}$. Both countries have therefore incentive to open to trade, and trade liberalisation yields:

$$
\Delta S W_{1}^{A, T \theta}=\Delta S W_{2}^{A, T \theta}=\frac{\Delta S W^{A, T \theta}}{2} .
$$

The required side payment is in favour of country 2 for

$$
\alpha \in] 0.452,0.478[; \quad \beta \in] \frac{15-8 \alpha[3+4 \alpha(1+\alpha)]}{8-32 \alpha}, 1[
$$

since in correspondence of this range we have that $\Delta S W_{1}^{A, T \theta}>\Delta S W_{2}^{A, T \theta}$. The opposite is true for the range which is complementary to $A$.

Anyway, this is not the unique range in which trade liberalisation may be mutually beneficial. From Proposition 5 total world welfare is shown to be strictly increasing in the following parameter ranges:

$$
\alpha \in] 0.425,0.452[; \beta \in] \frac{8 \alpha-9}{8-32 \alpha}, 1[; \quad \alpha \in] 0.452,0.5[; \beta \in] \frac{8 \alpha-9}{8-32 \alpha}, \frac{3-8 \alpha[1+2 \alpha(1+\alpha)]}{8-32 \alpha}[;
$$

respectively labeled as areas $B$ and $C$ in Figure 1 . In correspondence of these ranges the sign of the welfare differential is negative for at least one of the two countries: while area $B$ is characterized by a

\footnotetext{
${ }^{16} \Delta K_{i}^{A, j}$ with $i=1,2, j=T, T \tau, T \theta$, and $K=S W, C S, T C, p, \pi$, indicates the value of the differential from the autarkic equilibrium to the $j$-equilibrium for what concerns the magnitude $K$ in country $i$.
} 
gain for country 1 and a loss for country 2, the opposite is true for area $C$. In a supergame played over an infinite horizon, this problem could be effectively solved to generate a Pareto-efficient outcome. Applying Friedman (1971), i.e., the perfect folk theorem, the relevant condition is:

$$
\frac{1}{1-\delta}\left(\Delta S W_{i}^{A, T \theta}-T r_{i}\right) \geq \Delta S W_{i}^{A, T \theta}+\frac{\delta}{1-\delta} S W_{i}^{A},
$$

where $T r_{i}$ is the required side payment and $i=1,2$ respectively in B and C. It is straightforward to show that (3.19) requires

$$
\delta \geq \hat{\delta}_{i}=\frac{T r_{i}}{S W_{i}^{T \theta}-2 S W_{i}^{A}} .
$$

Condition (3.20) reveals that $S W_{i}^{T \theta}<2 S W_{i}^{A}$ suffices to ensure the sustainability of the Pareto-efficient equilibrium outcome at the subgame perfect equilibrium of the supergame. The latter condition is shown to hold for each $\alpha$ and $\beta$ in $C$ and for each $\alpha, \beta$ and $s>\frac{9-24 \alpha-48 \alpha^{2}-32 \alpha^{3}-24 \beta+288 \alpha \beta}{192 \alpha}$ in $B$. If instead $s_{M C}^{T \theta}<s<\frac{9-24 \alpha-48 \alpha^{2}-32 \alpha^{3}-24 \beta+288 \alpha \beta}{192 \alpha}$, the threshold value of the discount rate $\hat{\delta}_{1}$ is positive and it remains to be checked whether it lies below 1 . This happens for all $T r_{1}<S W_{1}^{T \theta}-2 S W_{1}^{A}$, whose r.h.s. is linear and decreasing in $s$. Therefore, region $B$ also hosts an additional subset of parameters in which the long run equilibrium generated by the supergame is Pareto-efficient:

$$
s \in\left(s_{M C}^{T \theta}, \bar{s}\right) ; T r_{1} \in\left(0, S W_{1}^{T \theta}-2 S W_{1}^{A}\right)
$$

where

$$
\bar{s} \equiv \frac{9-24 \alpha-48 \alpha^{2}-32 \alpha^{3}-24 \beta+288 \alpha \beta}{192 \alpha} .
$$

This portion of the parameter space is illustrated in Figure 2.

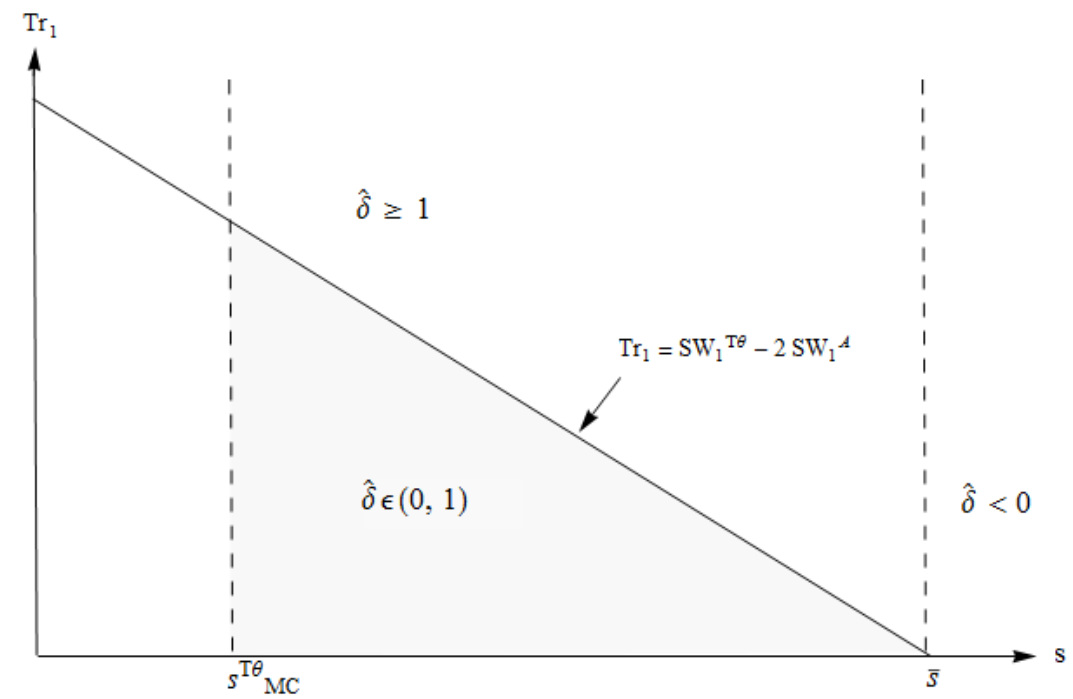

Figure 2: Threshold discount rate and side-payment, country 1, region $B$

\section{The larger country is brown}

As we have fully characterized the case in which the smaller country hosts the firm producing the brown good, we may now investigate the opposite case: the brown good is produced in the larger among the 
two countries. This implies no change in the autarkic equilibrium level of all magnitudes except for social welfare:

$$
S W_{1}^{A}=\pi_{1}^{A}+C S_{1}^{A} ; \quad S W_{2}^{A}=\pi_{2}^{A}+C S_{2}^{A}-\beta(1-\alpha) .
$$

At equilibrium, the above expressions write as follows:

$$
S W_{1}^{A}=\alpha\left(s-\frac{t \alpha^{2}}{12}-\beta\right) ; \quad S W_{2}^{A}=\frac{1}{12}(1-\alpha)\left[12 s-t(1-\alpha)^{2}\right] .
$$

Note that, while the social welfare of country 2 is negatively affected by the consumption of the brown good $\left(y_{22}^{A 1}=1-\alpha\right)$, this does not affect the social welfare of country 1 . Non negativity of both prices still requires imposing (2.8).

At the free trade equilibrium, Lemma 1 still obviously holds, together with (2.9-2.11). Full market coverage is now ensured if:

$$
s \geq s_{M C}^{T}=\frac{1}{4}[5+2 \beta]
$$

where again

$$
\left.s_{M C}^{T}>s_{p}^{A} \quad \forall \alpha \in\right] 0,1 / 2[, \beta \in] 0,1[,
$$

so that the condition for full market coverage in the long run also suffices to ensure the non-negativity of prices in autarky. We still have that, in equilibrium, $x_{1}^{T 1}=0, x_{2}^{T 1}=1, p_{1}^{T 1}=p_{2}^{T 1}=1, \hat{m}=1 / 2$ and $\pi_{1}^{T 1}=\pi_{2}^{T 1}=1 / 2$. Since the location of the marginal consumer is the same as in (2.10), the resulting total transportation costs and consumer surpluses are those in A.2, while social welfare levels are:

$$
S W_{1}^{T}=\frac{1}{2}-\alpha(1-s)-\frac{1}{3} \alpha^{3} ; S W_{2}^{T}=s(1-\alpha)+\alpha\left(1+\frac{1+\alpha^{2}}{3}\right)-\frac{6 \beta+7}{12} .
$$

\subsection{Trade liberalisation effects}

In view of the above considerations about the location of the indifferent consumer at the free trade equilibrium, the present framework fully retains the statements contained in Proposition 2-3. ${ }^{17}$ Notwithstanding this, from (4.1) and (4.3) we can state what follows:

Proposition 7 [Welfare] Trade liberalisation causes (i) an increase in the welfare of the smaller country if the latter is sufficiently small; (ii) a decrease in the welfare of the larger country, irrespective of countries' relative size; and (iii) an increase in the welfare at the world level for sufficiently high intensity of the emissions stemming from the consumption of the brown good and sufficiently small asymmetry in size between the two countries.

Proof. See Appendix A.

Proposition (7) thus implies that, when the polluting good is produced in the larger country, trade liberalisation may be, per se, welfare improving at the world level. Recalling (3.19) this applies provided that $S W_{1}^{T}<2 S W_{1}^{A}$ which is trivially shown to hold for each $\alpha, \beta$ and $s>\frac{3-6 \alpha-\alpha^{3}}{6 \alpha}$.

The elementary intuition for this result is that, if the brown firm is based in the larger country and the position of the indifferent consumer under trade liberalisation is independent of the location of the brown

\footnotetext{
${ }^{17}$ Note that in the case of profits, (2.13) still holds, but $s_{1}^{T}>s_{M C}^{T}$, which assures non-negativity of prices and full market coverage, is now met for $\alpha \in] 0,-1+\sqrt{2} \simeq 0.414[$ and $\beta \in] 0, \min \left[\frac{2-5 \alpha+\alpha^{3}}{2 \alpha}, 1[\right.$. This now implies that (2.13) holds, regardless of the level of $\beta$, for $\alpha \in] 0,0.289[$.
} 
production, then free trade here implies that the green firm necessarily penetrates the larger country and therefore some consumers in the latter have access to the green good. This reshuffling of aggregate demand at the world level in favour of the green variety reduces global pollution and opens the way to a welfare increase at the world level.

\section{Concluding remarks}

We have investigated how the environmental negative externality stemming from consumption affects trade in an international Hotelling duopoly where two firms, that differ in the greenness of their production, are located in asymmetric countries. We have shown that this kind of externality does not affect equilibrium demand partition: the firm located in the smaller country, whether producing a "brown" good or not, exports to the larger.

Our results can be contrasted with the original formulation of the model, where no environmental issues enter the picture (Lambertini (1997a)). In our primary framework (in which it is assumed that the brown good is produced in the smaller country), consumers' environmental awareness only implies a reduction in the social welfare of the smaller country under autarky, and a decrease in the social welfare of the larger country in case of trade liberalisation. On the contrary, in the same framework, the adoption of a trade policy by the government of the larger country has been shown to be effective in determining a change in the distribution of gains and losses stemming from bilateral opening to trade. In particular, there are admissible parameter ranges in which a Pigouvian tax on imports implies losses for the smaller country even when the latter is very small, while improving the performance of the larger one. More interestingly, an export subsidy for the firm producing the green good delivers a net gain from trade liberalisation accruing to both countries, provided that the asymmetry in size is sufficiently small and the emission intensity is sufficiently high. Hence, the presence of a significant negative externality in consumption may be crucial in convincing larger country's government to subsidise the firm producing a green good; the reason for this does not consist, as expected, in classic export subsidy arguments of import substitution, but rather in the fact that consuming a certain amount of the green good may turn out to be beneficial for the smaller country too, since benefits directly accruing to the society through reduction in local emissions may outweigh the decrease in firm's profits.

The alternative scenario, based on the assumption that the green firm be located in the larger country, yields intuitive results. Since market shares after trade liberalisation are the same as in the former setting, here we reach the straightforward conclusion that free trade indeed generates a welfare improvement at the world level because a portion of the population of consumers previously compelled to buy the brown variant turn to the green one. 


\section{References}

Antweiler, W., B. R. Copeland, and M. S. Taylor (2001): "Is Free Trade Good for the Environment?," American Economic Review, 91(4), 877-908.

Bagwell, K., and R. W. Staiger (2001): "Domestic Policies, National Sovereignty, And International Economic Institutions," The Quarterly Journal of Economics, 116(2), 519-562.

Bansal, S., and S. Gangopadhyay (2003): "Tax/Subsidy Policies in the Presence of Environmentally Aware Consumers," Journal of Environmental Economics and Management, 45(2, Supplement), 333355.

Brander, J. A., and M. S. TAYlor (1997): "International Trade and Open-Access Renewable Resources: The Small Open Economy Case," Canadian Journal of Economics, 30(3), 526-52.

Chichilnisky, G. (1994): "North-South Trade and the Global Environment," American Economic Review, 84(4), 851-874.

Clemenz, G. (2010): "Eco-Labeling and Horizontal Product Differentiation," Environmental and Resource Economics, 45, 481-497.

Conrad, K. (2005): "Price Competition and Product Differentiation When Consumers Care for the Environment," Environmental \&3 Resource Economics, 31(1), 1-19.

Copeland, B. R. (2011): Palgrave Handbook of International Tradechap. "Trade and the Environment", pp. 423-496. Palgrave MacMillan.

Copeland, B. R., and M. S. Taylor (1994): "North-South Trade and the Environment," The Quarterly Journal of Economics, 109(3), 755-87.

Copeland, B. R., and M. S. Taylor (1999): "Trade, Spatial Separation, and the Environment," Journal of International Economics, 47(1), 137-168.

Copeland, B. R., and M. S. Taylor (2003): Trade and the Environment: Theory and Evidence. Princeton University Press.

Copeland, B. R., and M. S. Taylor (2004): "Trade, Growth, and the Environment," Journal of Economic Literature, 42(1), 7-71.

(2005): "Free Trade and Global Warming: a Trade Theory View of the Kyoto Protocol," Journal of Environmental Economics and Management, 49(2), 205-234.

(2009): "Trade, Tragedy, and the Commons," American Economic Review, 99(3), 725-49.

D'Aspremont, C., J. J. Gabszewicz, and J.-F. Thisse (1979): "On Hotelling's "Stability in Competition"," Econometrica, 47(5), 1145-50.

Ederington, J., A. Levinson, And J. Minier (2004): "Trade Liberalization and Pollution Havens," The B.E. Journal of Economic Analysis \&3 Policy, 0(2), 6. 
Egger, H., And P. Egger (2007): "Outsourcing and Trade in a Spatial World," Journal of Urban Economics, 62, 441-470.

(2010): "The Trade and Welfare Effects of Mergers in Space," Regional Science and Urban Economics, 40(4), 210-220.

ERIKsson, C. (2004): "Can Green Consumerism Replace Environmental Regulation? A DifferentiatedProducts Example," Resource and Energy Economics, 26(3), 281-293.

Espinola-Arredondo, A., and H. Zhao (2011): "Environmental Policy in a Linear City Model of Product Differentiation," working paper, School of Economic Sciences, Washington State University, (2011-4).

Fischer, C., And A. K. Fox (2009): "Comparing Policies to Combat Emissions Leakage: Border Tax Adjustments versus Rebates," RFF Discussion paper.

Frankel, J., and A. Rose (2005): "Is Trade Good or Bad for the Environment? Sorting Out the Causality," Review of Economics and Statistics, 87(1), 85-91.

Friedman, J. W. (1971): "A Non-cooperative Equilibrium for Supergames," Review of Economic Studies, 38(113), 1-12.

FujiWara, K. (2009): "Why Environmentalists Resist Trade Liberalization," Environmental $\mathscr{E}^{3}$ Resource Economics, 44(1), 71-84.

Gros, D. (2009): "Global Welfare Implications of Carbon Border Taxes," CESifo working paper, (2790).

Haupt, A. (2006): "Environmental Policy in Open Economies and Monopolistic Competition," Environmental and Resource Economics, 33, 143-167.

Holland, S. P. (2009): "Taxes and Trading versus Intensity Standards: Second-Best Environmental Policies with Incomplete Regulation (Leakage) or Market Power," NBER working paper, (15262).

Keen, M., and C. Kotsogiannis (2011): "Coordinating Climate and Trade Policies: Pareto Efficiency and the Role of Border Tax Adjustments," Exeter University, Department of Economics working paper, (1106).

Lambertini, L. (1997a): "Trade Liberalization May Be Harmful under Endogenous Differentiation," Osaka City University Economic Review, 33(1), 237-254.

(1997b): "Unicity of the Equilibrium in the Unconstrained Hotelling model," Regional Science and Urban Economics, 27(6), 785-798.

McAusland, C. (2008): "Trade, Politics, and the Environment: Tailpipe vs. Smokestack," Journal of Environmental Economics and Management, 55(1), 52-71.

Moraga-González, J. L., and N. Padrón-Fumero (2002): "Environmental Policy in a Green Market," Environmental and Resource Economics, 22, 419-447.

Neary, J. (2006): "International Trade and the Environment: Theoretical and Policy Linkages," Environmental \&3 Resource Economics, 33(1), 95-118. 
Rodríguez-Ibeas, R. (2007): "Environmental Product Differentiation and Environmental Awareness," Environmental \& Resource Economics, 36(2), 237-254.

Shachmurove, Y., and U. Spiegel (1995): "On Nations Size and Transportation Costs," Review of International Economics, 3(2), 235-243.

Tabuchi, T., And J.-F. Thisse (1995): "Asymmetric Equilibria in Spatial Competition," International Journal of Industrial Organization, 13(2), 213-227.

TAYlor, M. (2011): "Buffalo Hunt: International Trade and the Virtual Extinction of the North American Bison," American Economic Review, 101(7), 3162-3195.

Tharakan, J., and J.-F. Thisse (2002): "The Importance of Being Small. Or when Countries are Areas and not Points," Regional Science and Urban Economics, 32(3), 381-408.

Yakita, A., And H. Yamauchi (2011): "Environmental Awareness and Environmental R\&D Spillovers in Differentiated Duopoly," Research in Economics, 65(3), 137-143.

Zeng, D.-Z., and L. Zhao (2009): "Pollution Havens and Industrial Agglomeration," Journal of Environmental Economics and Management, 58(2), 141-153. 


\section{A Autarky and free trade}

\section{A.1 Equilibrium magnitudes}

Autarkic equilibrium, relevant magnitudes others than social welfares:

$p_{1}^{A}=s-\frac{1}{4} \alpha^{2} ; \quad p_{2}^{A}=s-\frac{1}{4}(1-\alpha)^{2} ;$

$\pi_{1}^{A}=\frac{\alpha}{4}\left(4 s-\alpha^{2}\right) ; \quad \pi_{2}^{A}=\frac{1-\alpha}{4}\left[4 s-(1-\alpha)^{2}\right] ;$

$T C_{1}^{A}=\frac{1}{12} \alpha^{3} ; \quad T C_{2}^{A}=\frac{1}{12}(1-\alpha)^{3} ;$

$C S_{1}^{A}=\frac{1}{6} \alpha^{3} ; \quad C S_{2}^{A}=\frac{1}{6}(1-\alpha)^{3}$.

Free trade equilibrium, relevant magnitudes others than prices and profits:

$T C_{1}^{T}=\frac{\alpha^{3}}{3} ; \quad T C_{2}^{T}=\frac{1}{12}\left(1-4 \alpha^{3}\right) ;$

$C S_{1}^{T}=\alpha\left(s-1-\frac{1}{3} \alpha\right) ; \quad C S_{2}^{T}=s(1-\alpha)+\frac{1}{3}\left(3 \alpha+\alpha^{3}-\frac{13}{4}\right) ;$

$S W_{1}^{T}=\frac{1}{2}-\alpha\left(1-s+\beta+\frac{1}{3} \alpha^{2}\right)$

$S W_{2}^{T}=\frac{1}{12}\left\{-3-4(1+\beta)-2\left[6 s(-1+\alpha)-2 \alpha\left(3+\alpha^{2}\right)+(1-6 \alpha) \beta\right]\right\}$.

\section{A.2 Proof of Proposition 1}

Proof. In order to prove part (i) of Proposition 1 is sufficient to observe that:

$$
\begin{gathered}
S W_{1}^{T}-S W_{1}^{A}=\frac{1}{4}\left[2-\alpha\left(4+\alpha^{2}\right)\right]>0 \\
\text { iff } \quad \alpha \in] 0,0.4735[
\end{gathered}
$$

while, for what concerns part (ii) and (iii):

$$
\begin{aligned}
& S W_{2}^{T}-S W_{2}^{A}=\frac{1}{4}\left[\alpha\left(3+\alpha+\alpha^{2}+4 \beta\right)-2(1+\beta)\right] ; \\
& S W^{T}-S W^{A}=\frac{1}{4}[\alpha(\alpha+4 \beta-1)-2 \beta] ;
\end{aligned}
$$

where $S W^{j}$ is the social welfare at the world level, in correspondence of the $j$-equilibrium (with $j=$ $A, T, T \tau, T \theta)$. Both equations in (A.4) are strictly negative over the admissible range of parameters $\alpha$ and $\beta$.

\section{A.3 Proof of Proposition 2}

Proof. Consumer surpluses differentials w.r.t. autarky are defined as:

$$
C S_{1}^{T}-C S_{1}^{A}=\alpha(s-1)-\frac{1}{2} \alpha^{2} ; \quad C S_{2}^{T}-C S_{2}^{A}=\frac{1}{4}\left[6 \alpha+2(1-\alpha)\left(2 s-\alpha^{2}\right)-5\right] .
$$

Both strictly positive over the admissible parameter range $\alpha \in] 0, \frac{1}{2}[, \beta \in] 0,1[$. Then, since

$$
T C_{1}^{T}-T C_{1}^{A}=\frac{\alpha^{3}}{4} ; \quad T C_{2}^{T}-T C_{2}^{A}=\frac{1}{4} \alpha\left(1-\alpha-\alpha^{2}\right)
$$


are also positive over the admissible parameter range, trade liberalisation always determines an increase in transportation costs. This implies that, for both countries, the positive effect on consumers' surplus determined by the decrease in prices is strong enough to offset the negative one stemming from the dynamic of transportation costs.

\section{A.4 Proof of Proposition 7}

Proof. In order to prove part (i) of Proposition 1 is sufficient to observe that, again:

$$
\begin{gathered}
S W_{1}^{T 1}-S W_{1}^{A 1}=\frac{1}{4}\left[2-\alpha\left(4+\alpha^{2}\right)\right]>0 \\
\text { iff } \quad \alpha \in] 0,0.4735[,
\end{gathered}
$$

while, for what concerns part (ii):

$$
S W_{2}^{T 1}-S W_{2}^{A 1}=\frac{1}{4}\left[\alpha\left(3+\alpha+\alpha^{2}-4 \beta\right)-2(1-\beta)\right] ;
$$

where the latter is strictly negative over the admissible range of parameters $\alpha$ and $\beta$. With regards to part (iii) of the proposition, concerning welfare at the world level, we have that:

$$
\begin{aligned}
& S W^{T 1}-S W^{A 1}=\frac{1}{4}[2 \beta-\alpha(1-\alpha+4 \beta)]>0 \\
&\text { iff } \quad \alpha \in] 0,0.438[, \beta \in] \frac{\alpha(1-\alpha)}{2-4 \alpha}, 1[
\end{aligned}
$$

\section{B Trade policy}

\section{B.1 Equilibrium magnitudes}

Free trade equilibrium, relevant magnitudes for $\tau=\tau^{*}$ :

$$
\begin{aligned}
& p_{1}^{T \tau}=\frac{1}{3}(7-4 \alpha+2 \beta) ; \quad p_{2}^{T \tau}=\frac{1}{3}(5-2 \alpha+\beta) ; \\
& \pi_{1}^{T \tau}=\frac{1}{18}\left[-32 \alpha^{2}+(1-\beta)^{2}+2 \alpha(20+7 \beta)\right] ; \quad \pi_{2}^{T \tau}=\frac{1}{18}(5-2 \alpha+\beta)^{2} \\
& T C_{1}^{T \tau}=\frac{\alpha^{3}}{3} ; \quad T C_{2}^{T \tau}=\frac{1}{36}\left[3-12 \alpha^{3}+(2-2 \alpha+\beta)^{2}\right] ; \\
& C S_{1}^{T \tau}=\frac{\alpha[3 s+(4-\alpha) \alpha-2 \beta-7]}{3} ; C S_{2}^{T \tau}=\frac{36 s(1-\alpha)+4 \alpha[28-\alpha(11-3 \alpha)]-14 \beta+20 \alpha \beta+\beta^{2}-71}{36} ; \\
& S W_{1}^{T \tau}=\frac{1}{18}\left[2 \alpha(1-9 s+8 \beta)-8 \alpha^{2}-6 \alpha^{3}+(1-\beta)^{2}\right] ; \\
& S W_{2}^{T \tau}=\frac{1}{12}\left[12 s(1-\alpha)+4 \alpha\left(1+\alpha+\alpha^{2}\right)-2 \beta+8 \alpha \beta+\beta^{2}-3\right] .
\end{aligned}
$$


Free trade equilibrium, relevant magnitudes for $\tau=\bar{\tau}$ :

$$
\begin{aligned}
& p_{1}^{T \bar{\tau}}=3-4 \alpha ; \quad p_{2}^{T \bar{\tau}}=2(1-\alpha) ; \\
& \pi_{1}^{T \bar{\tau}}=(3-4 \alpha) \alpha ; \quad \pi_{2}^{T \bar{\tau}}=2(1-\alpha)^{2} ; \\
& T C_{1}^{T \bar{\tau}}=\frac{\alpha^{3}}{3} ; \quad T C_{2}^{T \bar{\tau}}=\frac{1}{3}(1-\alpha)^{3} ; \\
& C S_{1}^{T \bar{\tau}}=\frac{1}{3} \alpha[3 s+(12-\alpha) \alpha-9] ; \quad C S_{2}^{T \bar{\tau}}=\frac{1}{3}(1-\alpha)\left(3 s+8 \alpha-\alpha^{2}-7\right) ; \\
& S W_{1}^{T \bar{\tau}}=s \alpha-\frac{1}{3} \alpha\left(\alpha^{2}+3 \beta\right) ; S W_{2}^{T \bar{\tau}}=\frac{1}{3}\left(3 s-(1-\alpha)^{2}\right)(1-\alpha) ;
\end{aligned}
$$

Free trade equilibrium, relevant magnitudes for $\theta=\theta^{*}$ :

$$
\begin{aligned}
& p_{1}^{T \theta}=\frac{1}{4}+\alpha ; \quad p_{2}^{T \theta}=-\frac{1}{2}+2 \alpha \\
& \pi_{1}^{T \theta}=\frac{1}{32}(1+4 \alpha)^{2} ; \quad \pi_{2}^{T \theta}=\frac{1}{32}(1-4 \alpha)(20 \alpha-23) ; \\
& T C_{1}^{T \theta}=\frac{1}{3}(1-\alpha)^{3} ; \quad T C_{2}^{T \theta}=\frac{1}{24} \alpha[15+2 \alpha(4 \alpha-9)]-\frac{7}{64} ; \\
& C S_{1}^{T \theta}=\frac{1}{64}-\frac{1}{24} \alpha\left(9-24 s+18 \alpha+8 \alpha^{2}\right) ; C S_{2}^{T \theta}=\frac{1}{6}(1-\alpha)[1+6 s-2 \alpha(4+\alpha)] ; \\
& S W_{1}^{T \theta}=\frac{1}{64}(3-8 \beta)-\frac{1}{24} \alpha\left(3-24 s+6 \alpha+8 \alpha^{2}+12 \beta\right) ; S W_{2}^{T \theta}=s(1-\alpha)+\frac{\alpha}{2}+\frac{\alpha^{3}}{3}-\frac{13}{48} .
\end{aligned}
$$

\section{B.2 Optimal tariff, other effects}

In the presence of an optimal tariff, the long-run effect of trade liberalisation on country 1 still consists in an increase in her welfare for sufficiently low intensity of the emissions stemming from the consumption of the brown good. In fact, for $\left.\tau=\tau^{*}, \alpha \in\right] 0, \frac{1}{4}[$ and $\beta \in] 0,1-4 \alpha[$ :

$$
\begin{gathered}
S W_{1}^{T \tau}-S W_{1}^{A}=\frac{1}{36}\left[2(1-\beta)^{2}-16 \alpha^{2}-9 \alpha^{3}-4 \alpha(1-\beta)\right], \\
\text { iff } \beta \in] 0,1-\alpha-\frac{3 \sqrt{\alpha^{2}(2+\alpha)}}{\sqrt{2}}[.
\end{gathered}
$$

From Proposition 4 and (B.4) social welfare at the world level is strictly decreasing in the presence of an optimal tariff. For what concerns prices, transportation costs and consumer surpluses, the introduction of a tariff $\tau^{*}$ implies no differences in the sign of the dynamics from autarky to free trade, so as we can retain the claims of Proposition 2; for what concerns profits, on the other hand, free trade may bring about an increase in the profit accruing to the firm based in the smaller country if the latter is sufficiently small and the emission intensity is sufficiently small too, while it always hurts the firm based in the larger country. For what concerns firm 1, in fact, for $\left.\tau=\tau^{*}, \alpha \in\right] 0, \frac{1}{4}[$ and $\beta \in] 0,1-4 \alpha[$ :

$$
\begin{array}{r}
\pi_{1}^{T \tau}-\pi_{1}^{A} \quad=\quad \frac{9 \alpha^{3}+2(\beta-1-2 \alpha)^{2}+36 \alpha(2-2 \alpha+\beta)}{36}-s \alpha>0 \\
\text { iff } \quad s<s_{1}^{T \tau}=\frac{2+80 \alpha-64 \alpha^{2}+9 \alpha^{3}-4 \beta+28 \alpha \beta+2 \beta^{2}}{36 \alpha},
\end{array}
$$

where $s_{1}^{T \tau}$ is strictly decreasing in $\alpha$, with $\left.s_{1}^{T \tau} \in\right] \infty, \frac{129}{64}+\frac{\beta(3+2 \beta)}{9}[$ as $\alpha \in] 0, \frac{1}{2}\left[\right.$. Moreover $s<s_{1}^{T \tau}$ is necessary but not sufficient condition for (B.5) to hold in equilibrium since also $s_{1}^{T \tau}>s_{M C}^{T \tau}$, which assures non-negativity of prices and full market coverage, has to be met. The latter holds for $\alpha \in] 0,0.219[$ and 
$\beta \in] 0, \frac{2\left(1-7 \alpha^{2}\right)}{2+5 \alpha}-3 \sqrt{\frac{\alpha^{2}+10 \alpha^{3}+19 \alpha^{4}}{(2+5 \alpha)^{2}}}[$.

For what concerns firm 2 :

$$
\pi_{2}^{T \tau}-\pi_{2}^{A}=\frac{27-36 s(1-\alpha)-9 \alpha[3-(3-\alpha) \alpha]+2(2-2 \alpha+\beta)(8-2 \alpha+\beta)}{36}
$$

strictly negative over the whole admissible parameter range.

Hence, these results are not substantially different from those claimed in Proposition 3, except for the fact that profits accruing to firm 1 are shown to increase with free trade uniquely in correspondence of a stricter range of $\alpha$. For firm 1, in fact, the positive quantity effect of trade liberalisation $\hat{m}-\alpha$ is now decreasing in $\alpha$ by a factor $\frac{2}{3}$ (which is 1 for $\tau=0$ ), implying that the advantage of being located in the smaller country is reduced by $\frac{1}{3}$. In conclusion, differently from the claim contained in Proposition 1 ,

social welfare of country 1 is shown to be decreasing even when the latter is very small (for $\alpha \in] 0,0.25[$ ), provided that $\beta$ is high enough, that is $\beta \in] 1-\alpha-\frac{3 \sqrt{\alpha^{2}(2+\alpha)}}{\sqrt{2}}, 1-4 \alpha[$.

The emission intensity $\beta$, in fact, now enters in the long run equilibrium definition of all relevant magnitudes, through optimal tariff $\tau^{*}$. This has implications with regards to the dynamics of the social welfare in country 1 inasmuch as a higher $\beta$ is associated with a rise in the equilibrium price of the brown variety as well as with a decrease in demand accruing to firm 1 . While the former effect unambiguously leads to a decrease in consumer surplus for country 1's consumers, the combination of the two effects may entail an increase in profits for firm 1 , provided that $\alpha$ and $\beta$ are sufficiently high. ${ }^{18}$

Since the negative effect on consumer surplus is always greater than the positive effect on firm's profits, the free trade equilibrium social welfare of country 1 is strictly decreasing in $\beta$ :

$$
\left.\frac{\partial S W_{1}^{T \tau}}{\partial \beta}=\frac{1}{9}(-1-8 \alpha+\beta)<0 \quad \forall \quad \alpha \in\right] 0, \frac{1}{4}[, \quad \beta \in] 0,1-4 \alpha[.
$$

Moreover, since $\frac{\partial S W_{1}^{A}}{\partial \beta}=-\alpha$ (see 2.7), it is always true that $\frac{\partial S W_{1}^{T \tau}}{\partial \beta}<\frac{\partial S W_{1}^{A}}{\partial \beta}<0$. Thus, as $\beta$ rises, social welfare of country 1 is also necessarily reduced as compared to autarky.

\section{B.3 Sub-optimal tariff}

Trade liberalisation, in the presence of a sub-optimal tariff, brings about a decrease in both countries' social welfares. In fact, for $\tau=\bar{\tau}, \alpha \in] 0, \frac{1}{2}[$ and $\beta \in] 1-4 \alpha, 1[$ we have that

$$
S W_{1}^{T \bar{\tau}}-S W_{1}^{A}=-\frac{\alpha^{3}}{4} ; S W_{2}^{T \bar{\tau}}-S W_{2}^{A}=\frac{1}{4}(\alpha-1)^{3} ;
$$

are both strictly negative, which also implies $\Delta S W^{A, T \bar{\tau}}<0$. For what concerns consumer surpluses we have that

$$
C S_{1}^{T \bar{\tau}}-C S_{1}^{A}=-\frac{1}{6} \alpha\left[6(1-6 s)+4(3-6 \alpha)+3 \alpha^{2}\right] ; C S_{2}^{T \bar{\tau}}-C S_{2}^{A}=\frac{1}{2}(\alpha-1)\left(5-2 s-6 \alpha+\alpha^{2}\right) .
$$

Both differentials are strictly positive proven that $s>3-4 \alpha+\alpha^{2}$. For what concerns profits we have that

$$
\begin{aligned}
& \pi_{1}^{T \bar{\tau}}-\pi_{1}^{A}=-s \alpha+\frac{1}{36}\left[36(3-6 \alpha) \alpha+72 \alpha^{2}+9 \alpha^{3}\right] \\
& \pi_{2}^{T \bar{\tau}}-\pi_{2}^{A}=\frac{27+2(3-6 \alpha)(9-6 \alpha)+36 s(-1+\alpha)-9 \alpha[3+(-3+\alpha) \alpha]}{36}
\end{aligned}
$$

where both differentials are strictly negative.

$$
\left.18 \frac{\partial \pi_{1}^{T \tau}}{\partial \beta}<0 \quad \forall \quad \alpha \in\right] 0, \frac{1}{7}[, \quad \beta \in] 0,1-7 \alpha[.
$$




\section{B.4 Proof of Proposition 6}

Proof. For what concerns part (i), consider that strictly positive consumer surplus dynamics:

$$
C S_{1}^{T \theta}-C S_{1}^{A}=\frac{1}{4}(1-\alpha)[4 s-2 \alpha(2+\alpha)-3] ; \quad C S_{2}^{T \theta}-C S_{2}^{A}=\frac{1}{64}-\frac{1}{8} \alpha\left(3-8 s+6 \alpha+4 \alpha^{2}\right)
$$

are necessarily driven by the decrease in both prices since

$$
T C_{1}^{T \theta}-T C_{1}^{A}=\frac{8 \alpha[5-2(3-\alpha) \alpha]-7}{64} ; \quad T C_{2}^{T \theta}-T C_{2}^{A}=\frac{1}{4}(1-\alpha)^{3} ;
$$

are strictly positive. For what concerns part (ii):

$$
\pi_{1}^{T \theta}-\pi_{1}^{A}=\frac{1+8 \alpha\left[(1+\alpha)^{2}-4 s\right]}{32} ; \quad \pi_{2}^{T \theta}-\pi_{2}^{A}=\frac{8 \alpha[11-\alpha(7+\alpha)]-15-32 s(1-\alpha)}{32}
$$

both strictly negative over the whole admissible parameter range. 


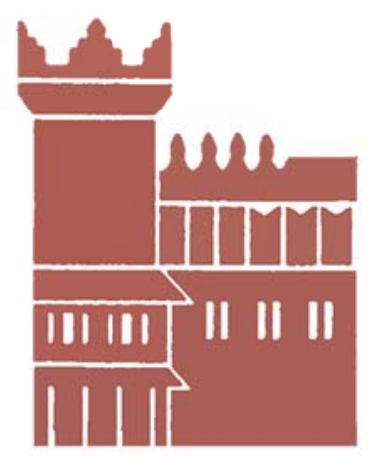

Alma Mater Studiorum - Università di Bologna DEPARTMENT OF ECONOMICS

Strada Maggiore 45

40125 Bologna - Italy

Tel. +39051 2092604

Fax +390512092664

http://www.dse.unibo.it 